\title{
Functional categories, morphosyntactic change, grammaticalization ${ }^{1}$
}

ANS van KEMENADE

The articles in this special issue are all broadly concerned with various aspects of the rise of grammatical items and functional categories and represent a variety of theoretical approaches to the analysis of the nature of such items. They arise out of a workshop held at the XIIIth International Conference on Historical Linguistics at Düsseldorf in August, 1997, titled "Functional Categories and Morphosyntactic Change." The term "functional categories" should be understood in a broad sense, comprising in general those linguistic categories that convey grammatical rather than lexical information (tense, mood, case, certain types of prepositions, and so on), as well as the more specific theoretical approach in which such categories are each assigned separate status as structurally represented phrases: current versions of the principles-andparameters approach spearheaded by Chomsky.

When we consider the types of work that fall in the sphere of morphosyntactic change, we see that they form roughly two subdomains: the first is the interaction between inflectional morphology and word order; the second is grammaticalization. These two subdomains in a way represent two sides of the same coin. Work on the interaction between inflectional morphology and word order usually concentrates on the loss of inflection and its effects in the syntax, which often involve the rigidification of word order. Work on grammaticalization, on the other hand, is concerned with how new grammatical morphemes develop out of syntactically and semantically impoverished lexical items. This recalls Givon's adage, "yesterday's syntax is today's morphology" (Givon 1975). We could argue then that the above two subdomains represent complementary responses to shifts in the balance between syntax and morphology, a classic problem of historical linguistics.

It is therefore remarkable that in practice the two domains are largely the subject of quite divergent ways of linguistic theorizing: the syntactic effects of inflectional morphology and the loss thereof are a favored topic in formal frameworks of grammar. One of the characteristics of formal approaches to 
grammar change is that they often assume abrupt discontinuity, at least at the level of the speaker's internalized grammar. Grammaticalization phenomena on the other hand have sparked their own broad theoretical approach, which may reasonably be called grammaticalization theory. A prominent feature of such theories is an emphasis on graduality, at least at the level of the language output. We can see, therefore, that the two domains are exploited for theories that on the face of it are best tailored to meet their respective empirical needs. Having said this we should, however, also note that these theoretical approaches are rather different, in some respects even incompatible, in their background assumptions. One of the key differences between the approaches is precisely in their object of research: while formal approaches aim at a characterization of the internalized grammar of the speakers, which is reflected only indirectly in the language facts at our disposal, grammaticalization theorists do not make any distinction between grammar and language output, indeed they probably believe that no such distinction is possible. To the extent that grammar can be separated from the rest of communicative competence, it is not seen as primary, but rather as being driven by discourse and other aspects of the communicative environment/cognition. Within such an approach, a grammaticalization process is then driven by semantic/cognitive/communicative factors, as the contribution by Haspelmath in this volume shows. From that perspective, it is, however, harder to view grammaticalization as a type of change that involves the interaction of morphology and syntax, since it would seem to be hard to express a relation between them. I will come back to this in a discussion of some further contrasts between the approaches below. On the other hand, in any approach in which inflectional and syntactic information can be formally related to each other, it should be possible to express both types of change more or less directly.

We can reasonably say that the two approaches outlined in a way represent two camps, which, to put it mildly, take less than full account of each other's work. It therefore seems worthwhile to compare and contrast the approaches in this introductory essay, with the aim of clarifying for the reader that, while the approaches do not share too many background assumptions, they complement rather than contradict each other in important ways. I will give an outline of the empirical and theoretical issues involved, mostly serving as a backdrop to the papers in this special issue, and bringing some arguments of my own to what is surely an ongoing discussion and, currently, a particularly lively part of the field of historical linguistics, witness the spate of recent work, such as the work gathered in Traugott and Heine (1991), Heine et al. (1991), Hopper and Traugott (1993), Battye and Roberts (1995), Hulk and van Kemenade (1993), van Kemenade and Vincent (1997), Campbell (1999), to name but a few. In section 1, I will discuss how the phenomena 
under consideration touch on the relation between syntax and morphology. In section 2, we will see how grammaticalization theory deals with them, and in section 3 how formal approaches deal with them. I will touch on issues in the individual papers as I go along and will draw together these observations in an overview in section 4 .

\section{Morphosyntactic change}

Let us first consider in some more detail the above argument that the two domains of change are really two sides of the same coin. I will present this argument from the point of view of a theory that has the potential of a precise characterization of morphological and syntactic properties, and hence of expressing a relationship between them.

The balance between inflection and syntax has been a perennial issue in historical linguistics: in recent work from various theoretical perspectives, much of the effort is devoted to an attempt at giving theoretical and empirical content to the traditional observation that rich inflectional systems tend to go together with relatively free word order, and that hence the loss of inflection tends to go together with the rigidification of word order. One often-mentioned example in this context is the fixing of work order in the history of English following the stepwise loss of nominal and verbal inflection in the course of the Middle English period. The term "often-mentioned" is used advisedly: it is notoriously difficult to make the correlation between loss of morphology and rigid word order with a precision that is both empirically accurate and theoretically satisfactory. It should therefore come as no surprise that many authors stick to mentioning the correlation without giving it precise substantiation, although some favorable exceptions should be noted. For instance, Allen (1995: chapter 10) attempts to give precise datings in this respect, without, however, making any claims about a necessary relationship between the loss of morphology and its syntactic effects.

Another well-known example, again from the history of English, is that of the changes in the system of mood marking in the late Middle English and early Modern periods. This case is particularly well known from the account in Lightfoot (1979) and the many responses, follow-ups, and further treatments, especially Plank (1984) and Warner (1993). The general observation is that, due to the loss of inflectional morphology marking the subjunctive mood, the modal verbs, which had become morphologically defective, syntactically restricted, and bleached of any lexical meaning they had had, were pressed into service as the syntactically fixed replacement of the original mood morphology. The many accounts in the literature vary along dimensions as noted above: grammaticalization theorists tend to emphasize the 
longterm typological character of the change (Plank 1984), and more generally the semantic/pragmatic nature of its driving forces and its unidirectionality. In what formal accounts there are of this cluster of change, there is an emphasis on abruptness. This is particularly true for Lightfoot's (1979) account, in which the modals changed from main verb to auxiliary status almost overnight, so to speak, in the sixteenth century. Warner $(1990,1993)$ had refined this story, while maintaining its substance: there was a noticeable shift in the categorization of modal verbs during the period identified by Lightfoot, which he sees as follows: from being a peripheral subclass of verbs, they shifted to a separate class of auxiliaries. Approaches such as those by Lightfoot should not be taken to suggest that change is not gradual; it is gradual at the level of the language output, but the reanalysis intended by Lightfoot is a reanalysis in the internalized grammar of a new generation of speakers, thus the surface graduality of change actually masks a series of punctuations at the level of the grammar, the necessary by-product of the acquisition of new grammars by successive generations of speakers. Likewise Roberts $(1985,1993)$, who also presents a framework that has the makings of expressing a direct relationship between morphological loss and the recategorization of modals as grammatical function words. This perspective is explicitly adopted also in the contributions to this special issue by Beths and by Roberts and Roussou, and it makes crucial use of the current generative practice of projecting grammatical/morphological information as a syntactic constituent according to the standard phrase-structure format. Thus, any substantive grammatical category like tense or mood is projected in $\mathrm{X}^{\prime}$ fashion. As such, it can find grammatical expression in various ways. Let us discuss this in a simplified version with the modals as a case in point:

(1)

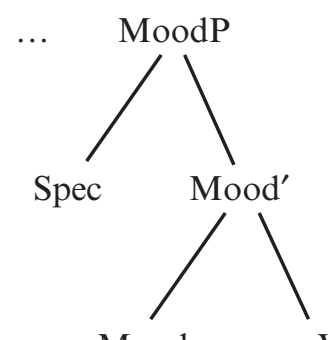

Mood

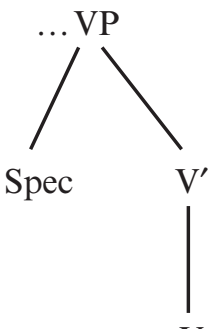


The first way in which the head of the MoodP containing specifications for Mood may be realized is by syntactic movement of a finite verb to its head Mood. At a stage where the modals were still main verbs of sorts ("of sorts" being the relevant term; modals had few nonfinite attestations in Old and Middle English), that is, when they were themselves the lexical head of a VP, the relevant verb could be a modal verb, and they were frequent there as early as Old English. Such a movement relation was transparent as long as the relevant morphology was there. But as the morphology was losing its distinctive force, and the morphologically defective modals became ever more firmly associated with the Mood position, there came a point when they were reanalyzed as function words base-generated in the head Mood. This is the essence of the idea pursued by Roberts and Roussou and by Beths in this special issue (and in references cited there), and this last stage is the final one in a grammaticalization process: base-generation as a functional head.

The relation between morphology and syntax finds a particularly direct expression in this perspective: inflectional morphology is part and parcel of the syntactic tree, and thus functional properties can be expressed by productive inflectional morphology (in minimalist terms, by checking inflected lexical heads against these properties). Alternatively, a closed class of free morphemes (the modal auxiliaries), which has a fixed association with a functional position, can come to be base-generated there.

The grammaticalization of the modals is one well-known example of the process whereby lexical items are transformed into grammatical function words. More on auxiliary systems can be found in Heine (1993), and a case study of one verb in Italian is Beninca and Poletto (1997). Other well-known cases are in Bybee et al.'s (1994) treatment of grammaticalization in systems for tense, mood, and aspect across languages in the world. A further case is that of the development of articles out of demonstrative pronouns in the Germanic and Romance languages, as treated in Abraham (1997), Philippi (1997), and Vincent (1997). The cases mentioned here have one remarkable property in common: much as they concern the development of a functional element out of a previously lexical one, the lexical meaning of the source element is not well defined to begin with. It is notoriously difficult to define the lexical meaning of any particular modal verb; semantic descriptions invariably rely quite heavily on context. Another case in point is Vincent's (1997) treatment of the development of the Romance articles out of the Latin deictic pronouns ipse and ille. Deixis itself is, of course, a category that depends completely on context. This suggests that those elements that have underspecified lexical meaning to begin with are a good deal more prone to grammaticalization than others (this is observed also in Beths's 
contribution here); indeed this may seem to be a fundamental property of grammaticalization. ${ }^{2}$

In the following sections, I will compare the various basic perspectives on morphosyntactic change in general and grammaticalization in particular in a bit more detail, starting with what we might call grammaticalization theory.

\section{Grammaticalization and grammaticalization theory}

Grammaticalization theory in a general sense refers to a framework for the study of language that focuses on how grammatical forms arise. Its orientation is functionalist and it calls into question a number of the basic axioms of structural linguistics, such as the notion of the discreteness of categories, the strict separation of diachronic and synchronic dimensions in language, the autonomy of each of the domains of grammar (e.g. the autonomy of syntax), the split between competence and performance, langue and parole, etc. The idea has arisen that the rules and categories of grammary are fluid, that categorization is in terms of clines rather than discrete categories, and that the notion of a synchronic stable stage is unwarranted even as an idealization. Another aspect that is stressed, as noted above, is that grammar arises out of discourse, and that therefore discourse factors must be taken into account much more seriously than is done in theories that advocate a strict separation between the grammatical system and aspects of language use.

Grammaticalization is a process whereby a lexical item develops into a grammatical marker. This is accompanied by phonetic and phonological reduction, loss of syntactic independence and lexical meaning. The cline of reduction is expressed by Hopper and Traugott (1993: 7) as follows:

(2) content item $>$ grammatical word $>$ clitic $>$ inflectional affix $>$ zero

In grammaticalization theory, several aspects of this type of change are strongly stressed. Grammaticalization is generally viewed as a longterm GRADUAL and UNIDIRECTIONAL process, that is, according to grammaticalization theorists the cline given in (2) cannot follow a reversed course. This unidirectionality is said to apply at all levels, semantic, syntactic, and phonological. While some grammaticalization theorists regard unidirectionality as a hypothesis subject to empirical verification, Haspelmath in this issue takes a very strong position and really regards it as an axiom for which a principled account is needed.

Grammaticalization theorists almost invariably view the process as being SEMANTICALLY DRIVEN; the bleaching of lexical meaning plays a 
primary role. Bybee et al. (1994: 17-18) go as far as to say that we can reconstruct the path of grammaticalization with the help of the "hypothesis that semantic change is predictable."

The observed graduality of the process, in conjunction with its unidirectionality, is taken to suggest that grammaticalization is an evolutional continuum, a diachronic force that has an impetus of its own. The idea of graduality is also closely connected with the prominent position of semantic change in grammaticalization theory. Semantic and grammatical changes are considered as interdependent, with semantic change leading to syntactic and morphological change almost automatically. It is evident, then, that the relation between semantic change and syntactic and morphological change is presupposed, but it is hard to see how this can be expressed. The semantic change involved is usually one in lexical meaning, whereas syntactic and morphological changes involve the constructional level.

The emphasis on unidirectionality has also led to the idea that the process is itself a mechanism of change. This is precisely what Haspelmath in his contribution to this volume aims to account for with his model of communication, following up on Keller's (1990) invisible-hand theory.

\section{Formal models of morphosyntactic change}

A brief sketch was given above of how a framework with generativestyle functional categories might deal with the changes in the system of modality marking in the history of English, in which a set of functional items with fixed syntactic status compensates for loss of inflection, so to speak, thus in a way creating new morphology. A more refined version of this can be found in Beths's contribution to this volume; and a survey of a number of cases in various languages analyzed from this perspective can be found in Roberts and Roussou's contribution. The cases discussed in Roberts and Roussou in essence all follow the same course. Following on a long period during which a lexical head is moved to a functional head, the relevant morphology is lost and the erstwhile lexical head is "frozen," that is, comes to be base-generated in the functional position.

I will now consider the conceptual side of this approach in more detail, to clarify how it might deal with the issues discussed in the previous sections.

It should be clear that we are now looking at cases of grammaticalization as an empirical phenomenon, but analyzed from a different perspective. Some prominent characteristics of grammaticalization phenomena discussed above are that they are very often cases of longterm change 
(although see Bruyn 1995 for discussion of grammaticalization in cases of sudden change resulting from language contact), which often follow one inexorable course (unidirectionality) that seems to be semantically driven. An approach in terms of generative-style functional categories will yield a different view of grammaticalization. A first and foremost difference will be that, although this type of change often spans a long period of time, it cannot conceivably be a mechanistic process with an impetus of its own. This is because the analytic perspective is now so very different. The object of research in a generative approach is the grammar acquired by each new language learner/speaker. Because each new learner constructs its own grammar, it is inconceivable that grammaticalization should be a diachronic process. While there is continuity in the language output, each new grammar acquired by speakers will simply assign the best-fitting status to the material encountered in the language environment. Thus, each grammar represents a stage in a series of synchronies and cannot have any diachronic status.

It is of some interest to see how concepts like unidirectionality are dealt with in this approach. Let it first be noted that Beths's contribution to this volume is a detailed case study of the single verb dare in the history of English that casts some doubt on the notion of unidirectionality. He shows that the main-verb uses of the verb dare arose later than the auxiliary uses, and that it is therefore possible to acquire argument structure and thereby gain lexical content. This point will be taken up further below. Beths aptly notes that in his generative-style functionalcategories approach, movement of a lexical head to a functional head position represents the synchronic instantiation of what grammaticalization theorists regard as a diachronic process: the movement is from the lexical to the functional and would therefore seem to correspond with the notion of unidirectionality. This provides the general rationale for grammaticalization in this perspective as noted above: over an often long period of movement of a lexical element to a functional position, the morphology that makes this movement dependency transparent for the learner is lost. If the relevant lexical item is one amenable to grammaticalization (in the sense of having underspecified lexical meaning and fitting in with the relevant functional meaning, as in the case of modals and mood), it may come to be base-generated in the functional position, whereby the movement dependency is eliminated. If it has full lexical content, for instance when it is a finite lexical verb, the movement dependency is eliminated in a different way: the verb no longer undergoes movement. We can see such a dual development in the changes in the English verb system during the late Middle English and early Modern periods: the auxiliation of the modal verbs following on the loss of mood 
inflection was noted above and is repeated here for convenience. We add two further changes to complete the picture:

(3) a. morphology marking the subjunctive mood was lost, and in the indicative mood, singular/plural contrasts were to a large extent lost;

b. modal verbs were in the final stages of becoming auxiliaries, losing the last of their main-verb properties;

c. finite main verbs ceased to occur on the left of adverbs, negative or otherwise, in sentences like He saw not John, which were standard in the fourteenth century;

d. the rise of periphrastic do is observed.

(3a) and (3b) have already received ample attention in the above. For accessible discussion of much of the literature of this whole constellation of change, the reader is referred to Denison (1993).

For the sake of exposition and oversimplifying somewhat, I will again take the diagram in (2) as a starting point. If we take (3c) and (3d) into account in the overall picture, it takes on an extra dimension: the insight that has emerged from the work of Roberts (1985, 1993), Kroch (1989), and Pollock (1989), with detailed substantiation from Warner (1993), is that the position of finite verbs to the left of not became specialized for modal auxiliaries and $d o$, whereas finite lexical verbs came to occur exclusively on the right of not. If we formalize this in terms of the tree diagram (1) and assume that not marks the left edge of the VP (to avoid complicating the argument with a discussion on negation, for which the reader is referred to van Kemenade [forthcoming]), we can now say that the essence of this sequence of change is that modals and rising periphrastic $d o$ came to be base-generated in the Mood position, and lexical finite verbs ceased to be moved here. Mood thus became the exclusive domain of auxiliaries, an insight due to Roberts (1985) and pursued vigorously and productively by a number of others. ${ }^{3}$ The loss of this verb-movement strategy, which took place broadly in the early Modern English period and whose precise date is controversial (see Warner 1997 and references there), has been related among others to the loss of finite verb inflections in the course of the Middle English period, in particular the loss of subjunctive morphology and the loss of singular/plural contrasts.

This brings us back to the argument on which I started this discussion: whatever the merits or otherwise of a framework with a supermarket of functional projections, it does allow a direct and insightful expression of the relation between syntactic developments and the creation of new morphology as a result of grammaticalization. Since syntax and inflectional morphology make use of the same structure, the syntactic effects 
of the loss of inflection are likewise directly expressible. This can be seen in the same case study: when the relevant morphology was productively there, both main verbs and the pre-auxiliaries were moved to the relevant functional head position Mood. When it was lost, the modals became more firmly associated with the Mood position, while lexical verbs ceased to be so associated. They acquired a fixed position as the head of a VP.

It is important to see that this framework puts an emphasis on the morphosyntactic aspects of both of the domains of change under discussion here; the role of semantic change that is so important in grammaticalization theory is underilluminated. Nevertheless a few observations are in order. It was observed above that the kinds of lexical item that form the input of grammaticalization tend to have underspecified, context-dependent meanings to begin with. Apart from this, it is of course not the case that functional projections have no meaning. Their meaning is constructional rather than lexical. We could well argue, therefore, that movement of a lexical item to a functional head implies a gain in functional/constructional meaning (this may well feed into Hopper and Traugott's observed gain in pragmatic meaning [1993: 87-93]). There seems to be a perspective here, then, for the role of semantic change as well.

The contribution to this collection by Weerman and de Wit is one that is firmly grounded in the generative-style functional-categories approach and is typically concerned with the syntactic effects of the loss of inflection, in this case of the effects of the loss of genitive inflection in the history of Dutch. The spirit of the approach should be familiar by now: as case inflection is lost, the structures it licenses are lost and have to be replaced by other syntactic means. Weerman and de Wit explicitly assume that case as a functional head licenses a DP, and that, upon the loss of case, a new licenser needs to be found. Two constructions subsequently arose: one with a possessive pronoun, the other with a preposition. Such an approach offers a direct expression for the intuition that the function of case is taken over by prepositions when case is lost. This raises the issue of the status of prepositions, which in their properties rather persistently straddle the divide between lexical and functional elements. There is some discussion in the literature that there is motivation for two types of preposition: one lexical and one functional (e.g. Rooryck 1996). Presumably, the preposition taking over the function of the genitive case in Weerman and de Wit's account would be of the functional kind, since it takes over the function of a case form.

The contribution by Vincent engages in debate with several of the issues discussed so far and also adopts a rather different formal approach than the one discussed so far. There are two main angles: one is with 
respect to issues concerning grammaticalization; the other is on types of preposition and the kind of formalism that they require. I will discuss them in turn.

There is an interesting argument here with respect to the unidirectionality of grammaticalization: starting on the one hand from the observation by grammaticalization theorists that grammaticalization always and only involves loss of meaning, and on the other hand from Roberts's (1985) follow-up that loss of meaning entails loss of argument structure, Vincent shows that many prepositions in Latin derive from adverbs. A change from adverb to preposition can reasonably be seen as a case of grammaticalization, since it is a change that involves the entrenchment of a once-independent constituent in a system of grammatical marking. But a change from adverb to preposition entails a GAIN in argument structure, as the relevant prepositions acquire complements.

Vincent also argues strongly that a distinction between lexical preposition and case marker such as that made in Rooryck (1996) is not feasible. He argues instead, against the background of the LFG framework of Bresnan (1982) and subsequent work, that the prepositions in question are basically of the same type and category, but that in their functional structure, differing uses may be defined. This approach resolves the tension between lexical and functional properties by differentiating between prepositions as one category defined in the categorial structure, and two different uses defined in their functional structure.

\section{Overview}

In the above exposition of the issues concerning morphosyntactic change and grammaticalization from various perspectives, much reference has been made to the individual papers in this collection, where they touch on the issues under discussion. Nevertheless, a brief summary of the main issues in each paper may be helpful. I will do this in order of appearance.

Roberts and Roussou discuss a number of cases of grammaticalization familiar from the literature and provide a novel account for this from the point of view of Chomsky's minimalist program (Chomsky 1995). This account still makes crucial use of the functional-categories approach, in which lexical items are ultimately reanalyzed as functional heads.

Haspelmath takes the unidirectionality of grammaticalization as axiomatic. He argues that potential counterexamples, such as the verb up, derived from the preposition up, as in they upped the cost for the public, are really cases of conversion. He then proceeds to give a pragmatic 
account for the existence of unidirectionality, based on Keller's (1990) invisible-hand theory of language change.

Beths gives a detailed case study of the history of a single verb, dare, in English. In the present-day language, dare clearly has both main-verb and auxiliary properties. Beths shows in detail that the main-verb properties of dare came up later than the auxiliary properties and gives an account for this in a framework with functional projections.

Vincent traces the early history of Latin prepositions that derive historically from an adverbial source and argues that, as a gain in argument structure, this suggests that the semantic bleaching characteristic of grammaticalization does not necessarily correspond with loss of argument structure. He furthermore argues that the properties of prepositions can be handled straightforwardly from an LFG perspective, in which a distinction is made between categorial and functional structure.

Weerman and de Wit trace the loss of genitive inflection in the history of Dutch and present an analysis of the two syntact constructions that came into the language as a result.

Catholic University of Nijmegen

\section{Notes}

1. I am grateful to Frank Beths and to Nigel Vincent for ongoing discussion about morphosyntactic change, and for their comments on an earlier draft of this introduction. Correspondence address: Opleiding Engels, Katholieke Universiteit Nijmegen, Erasmusplein 1, Postbus 9103, NL 6500 HD Nijmegen, The Netherlands. E-mail: A.v.Kemenade@let.kun.nl.

2. This obviously does not cover all cases of grammaticalization that can be found in the literature, e.g. the case discussed by Hopper and Traugott of speech-act verbs grammaticalizing to subordinating conjunctions, presumably purely on the basis of surface position. We can still say, however, even for these cases, that they take place in the left edge of the embedded clause, which is typically the functional rather than the lexical domain.

3. Roberts (1985) calls the relevant position I. The story here is simplified in various ways for expository purposes.

\section{References}

Abraham, Werner (1997). The interdependence of case, aspect and referentiality in the history of German: the case of the verbal genitive. In Parameters of Morphosyntactic Change, Ans van Kemenade and Nigel Vincent (eds.), 29-61. Cambridge: Cambridge University Press.

Allen, Cynthia L. (1995). Case Marking and Reanalysis. Oxford: Clarendon. 
Battye, Adrian; and Roberts, Ian (1995). Clause Structure and Language Change. Oxford: Oxford University Press.

Beninca, Paula; and Poletto, Cecilia (1997). The diachronic development of a modal of necessity. In Parameters of Morphosyntactic Change, Ans van Kemenade and Nigel Vincent (eds.), 94-118. Cambridge: Cambridge University Press.

Bresnan, Joan (ed.) (1982). The Mental Representation of Grammatical Relations. Cambridge: MA: MIT Press.

Bruyn, Adriënne (1995). Grammaticalization in Creoles. Unpublished dissertation, University of Amsterdam.

Bybee, Joan; Perkins, Revere; and Pagliuca, William (1994). The Evolution of Grammar, Tense, Aspect, and Modality in the Languages of the World. Chicago: University of Chicago Press.

Campbell, Lyle (ed.) (1999). On cons \& pros of "grammaticalization theory." Language Sciences 21 (special issue).

Chomsky, Noam (1995). The Minimalist Program. Cambridge, MA: MIT Press.

Denison, David (1993). English Historical Syntax. London and New York: Longman.

Givón, Talmy (1975). Serial verbs and syntactic change: Niger-Congo. In Word Order and Word Order Change, Charles Li (ed.), 47-112. Austin: University of Texas Press.

Heine, Bernd (1993). Auxiliaries. Oxford: Oxford University Press.

-; Claudi, Ulrike; and Hünnemeyer, Friederike (1991). Grammaticalization. A Conceptual Framework. Chicago: University of Chicago Press.

Hopper, Paul; and Traugott, Elisabeth C. (1993). Grammaticalization. Cambridge: Cambridge University Press.

Hulk, Aafke; and van Kemenade, Ans (eds.) (1993). Null subjects in diachrony. Lingua 89 (special issue).

Keller, Rudi (1990). Sprachwandel: Von der unsichtbaren Hand in der Sprache. Tübingen: Franke.

Kroch, Anthony (1989). Reflexes of grammar in patterns of language change. Language Variation and Change 1, 199-244.

Lightfoot, David (1979). Principles of Diachronic Syntax. Cambridge: Cambridge University Press.

Philippi, Julia (1997). The rise of the article in the Germanic languages. In Parameters of Morphosyntactic Change, Ans van Kemenade and Nigel Vincent (eds.), 62-93. Cambridge: Cambridge University Press.

Plank, Frans (1984). The modals story retold. Studies in Language 8, 305-364.

Pollock, Jean-Yves (1989). Verb movement, universal grammar and the structure of IP. Linguistic Inquiry 20, 365-424.

Roberts, Ian (1985). Agreement parameters and the development of English modal auxiliaries. Natural Language and Linguistic Theory 3, 21-58.

-(1993). Verbs and Diachronic Syntax: A Comparative History of English and French. Dordrecht, Boston, and London: Kluwer Academic.

Rooryck, Johan (1996). Prepositions and minimalist case marking. In Studies in Comparative Germanic Syntax II, Höskuldur Thráinsson, Samuel Epstein, and Steven Peter (eds.), 220-256. Dordrecht and Amsterdam: Kluwer.

Traugott, Elizabeth C.; and Heine, Bernd (eds.) (1991). Approaches to Grammaticalization, 2 vols. Amsterdam and Philadelphia: Benjamins.

van Kemenade, Ans (forthcoming). A formal perspective on grammaticalization: Jespersen's cycle revisited. In Diachronic Syntax: Models and Mechanisms, Susan Pintzuk, Georges Tsoulas, and Anthony Warner (eds.). Oxford: Oxford University Press. 
-; and Vincent, Nigel (eds.) (1997). Parameters of Morphosyntactic Change. Cambridge: Cambridge University Press.

Vincent, Nigel (1997). The emergence of the D-system in Romance. In Parameters of Morphosyntactic Change, Ans van Kemenade and Nigel Vincent (eds.), 149-169. Cambridge: Cambridge University Press.

Warner, Anthony (1990). Reworking the history of English auxiliaries. In Papers from the 5th International Conference on English Historical Linguistics, Sylvia Adamson et al. (eds.), 537-558. Amsterdam: Benjamins.

-(1993). English Auxiliaries: Structure and History. Cambridge: Cambridge University Press.

-(1997). Predicting the progressive passive: parametric change within a lexicalist framework. Language 71, 533-557. 